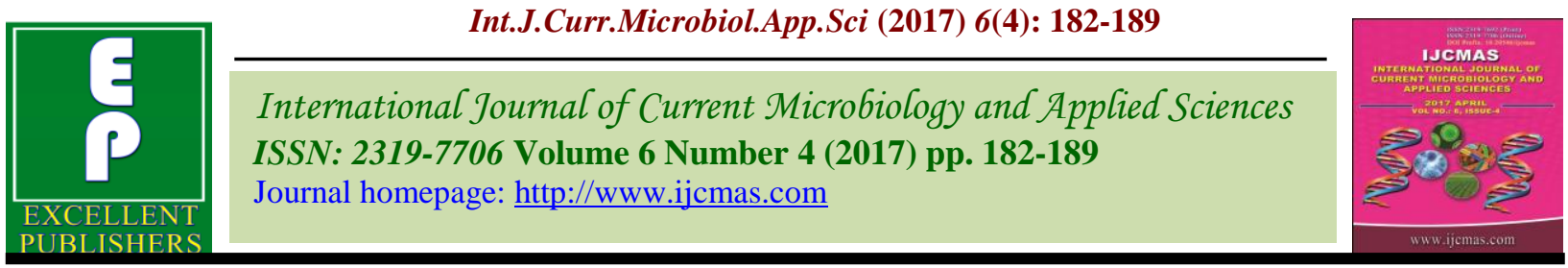

Original Research Article

https://doi.org/10.20546/ijcmas.2017.604.021

\title{
Design and Development of Updraft Gasifier Using Solid Biomass
}

\author{
R. Preetha Devi ${ }^{*}$ and S. Kamaraj ${ }^{2}$ \\ ${ }^{1}$ Department of Bioenergy, AEC \& RI, TNAU, Coimbatore-03, India \\ ${ }^{2}$ International Institute of Renewable Energy, NERD Society, Vadavalli, Coimbatore, India \\ *Corresponding author
}

\begin{tabular}{|c|c|}
\hline & A B S T R A C T \\
\hline $\begin{array}{l}\text { Ke y w or d s } \\
\text { Biomass } \\
\text { gasification, } \\
\text { Bioenergy, Wood } \\
\text { chips, Coconut husk }\end{array}$ & \multirow{3}{*}{$\begin{array}{l}\text { Due to fast climate change and foreseen damage through global warming, access to clean } \\
\text { and green energy has become very much essential for the sustainable development of the } \\
\text { society, globally. Biomass based energy is one of the important renewable energy } \\
\text { resources to meet the day to day energy requirements and is as old as the human } \\
\text { civilization. Biomass gasification is among few important aspects of bioenergy for } \\
\text { producing heat, power and biofuels for useful applications. The gas from biomass gasifier } \\
\text { contains quantities of particulates, tars, and other constituents that may exceed the } \\
\text { specified limits which may hinder their safe usage in applications where tar free clean gas } \\
\text { is required such as in automobile engines. To determine performance of pilot model } \\
\text { updraft gasifier with use of wood chips, coconut husk, coconut shell and pressed sugar } \\
\text { cane biomass solid fuels at used weight of } 30 \mathrm{Kg} \text {. }\end{array}$} \\
\hline Article Info & \\
\hline $\begin{array}{l}\text { Accepted: } \\
\text { 02 March } 2017 \\
\text { Available Online: } \\
10 \text { April } 2017\end{array}$ & \\
\hline
\end{tabular}

\section{Introduction}

The world community is more accentuating on the clean and green energy for the sustainable development of the society and certain concerns and potentials are being discussed about switching to renewable energy (solar, biomass, wind etc.) for different but specific claims. Prior to the use of fossil fuel, the biomass was the main source of cooking, heating and electrical applications. However, with the introduction of fossil fuels such as petroleum products, coal, natural gas, etc. the world becoming dependent on these fuels and nearly $80 \%$ of the total energy requirement is being met by these fuels causing severe environmental problems, globally. Also, biomass is considered to be the prominent form of energy and having a significant share (10-14\%) in the global energy load, while it has major share up to $90 \%$ of total energy supply in the remote and rural areas of the developing world. It is also likely to remain the main source of primary energy feedstock for the developing countries in the near future as around $90 \%$ of the world population is expected to reside in the developing countries by 2050 (Kucuk and Demirbas, 1997; Sims, 2003; Pathak et al., 2013).

Gasification is a promising technology which allows for converting a solid fuel into a gas which is easier to clean, transport and burn efficiently and it keeps $70-80 \%$ of the chemical energy of the original fuel. Moreover, gas from gasification can be used in a wide range of applications: production of 
heat and power, and as feedstock for the synthesis of fuels and chemicals. In the case of small-scale power generation or decentralized systems, gasifiers coupled to internal combustion engines lead to overall efficiencies higher than those of conventional systems. The advantages associated with the gasification technology are added into those of using biomass. In fact, biomass gasification could contribute to the development of rural areas by using local wastes to produce electricity. However, biomass gasification has not being widely used at commercial scale because of many challenges associated with feeding issues and supply chain management. Although biomass is available locally all over the world, it is widely distributed across regions. For example, firewood is distributed throughout the forest and the biomass collected is irregular in size and it has a very significant moisture content, which makes it difficult to transport and thus to feed into the gasifier unit (thus requiring high investment costs to achieve the necessary properties). For small-scale fixed bed gasifiers, cutting and/or sawing of wood blocks is the preferred form of fuel preparation. The size range of chips can be chosen by screening such that the fuel is acceptable for a specific gasifier type. This problem is even more important in large-scale plants due to the huge amount of biomass required (Ghosh et al., 2006).

\section{Updraft gasifier}

Updraft gasifier is suitable for the solid biomass which has high-moisture (up to $60 \%$ ), high-ash (up to $25 \%$ ) and low-volatile fuels such as charcoal and it is also called as a countercurrent gasifier. Updraft gasifier has some advantages over downdraft gasifiers such as, good thermal efficiency, flexible with moisture content, small pressure drop across the reactor, low tendency of slag formation etc. and has been studied by number of researchers (James et al., 2014, Yadav et al., 2013, Ismail and El-Salam, 2014, Raja et al.,
2015, Nsamba et al., 2015) for the last several decades. Updraft is more suitable for direct firing, where the gas produced is burnt in a furnace or boiler without cleaning or cooling. Biomass is fed from the top of the gasifier and a gasifying medium (air) is fed from the bottom of the gasifier. In this countercurrent reactor, the product gas leaves from the top while solids fuels and ash leave from the bottom. The design of the gasifier can be a major influence on the amount of tar in the product gas.

\section{Materials and Methods}

\section{Description of the updraft gasifier}

The length of $1 \mathrm{~m}$ biomass was fixed in parallel position in the reactor and slowly combusted with air. Outer layer of the biomass is first cracked and then, followed by other portion, is converted into char. Tars travel from bottom to top direction. Because of pyrolysis zone temperature was around $600-800^{\circ} \mathrm{C}$, most of the tars was thermally cracked and the product gas is almost tars free. Chen et al., (2003) reports that the liquid fraction hits a maximum at about $500^{\circ} \mathrm{C}$ and suggests that gas formation is more prominent from this point due to the liquid fraction being cracked at temperatures above $500^{\circ} \mathrm{C}$, by thermally decomposing, not only the tars amount in the final gas product is minimized but also the yield of producer gas is increased as tars are converted into smaller molecular components. The temperature at which tars are cracked is reported to be between 700 and $1250{ }^{\circ} \mathrm{C}$ (Umeki et al., 2012). The most of the updraft fixed bed gasifiers use wood chips and coconut shell and their performances have been widely studied (Di Blasi, 2004 and Prabir Basu, 2013).

\section{Updraft gasifier design process}

Gasifier design involves both process and hardware. The process design involves the 
type of the gasifier and yield of the producer gas, operating conditions, and the size of the reactor. The hardware design involves structural and mechanical components, such as grate, main reactor body, insulation, and others, that are specific to the reactor type (Ciferno and Marano, 2002).

\section{Design specification of updraft gasifier}

Specification of the plant is very important for the design of the gasifier. The input includes the specification of the fuel, gasification medium, and product gas. A typical fuel specification will include proximate and ultimate analysis, operating temperatures, and ash properties. The specification of the gasifying medium is based on the selection of steam, oxygen, and or air and their proportions. Here the updraft gasifier is designed based on the air gasifying medium

\section{Design parameters of the updraft gasifier as follows}

The desired heating value of the product gas dictates the choice of gasification medium. If air is the gasification medium, the lower heating value (LHV) of gas is in the range of $47 \mathrm{MJ} / \mathrm{m}^{3}$ (Yadav et al., 2013). It may be noted that when the feedstock is biomass, the heating value is lower due to its high oxygen and moisture content.

Capital cost is lowest for air, followed by steam. A much larger investment is needed for an oxygen plant, which also consumes a large amount of auxiliary power.

Equivalence ratio (ER) has a major influence on carbon conversion efficiency. For the product gas, the specification includes, desired gas composition, heating value, production rate $\left(\mathrm{N} \mathrm{m}^{3} / \mathrm{s}\right.$ or MWth produced),yield of the product gas per unit fuel consumed required power output of the gasifier, Q.
The outputs of process design include geometric and operating and performance parameters. The geometric or basic size includes reactor configuration, cross-sectional area, and height (hardware design). Important operating parameters are (i) reactor temperature, (ii) preheat temperature of air and (iii) amount (i.e., air/biomass ratio) and relative proportion of the gasifying medium (i.e., air loxygen ratio). Performance parameters of a gasifier include carbon conversion and cold-gas efficiency.

A typical gasifier process design starts with a mass balance followed by an energy balance. Here we describe the calculation procedures for these.

\section{Mass balance}

Basic mass and energy balance is common to all types of gasifiers. It involves calculations for product gas flow and fuel feed rate.

\section{Product gas flow-rate}

The gasifier's required power output, Q $\left(\mathrm{MW}_{\mathrm{th}}\right)$, is an important input parameter specified by the requirement. Based on this, we made a preliminary estimation of the amount of fuel to be fed into the gasifier and the amount of gasifying medium. The volume flow-rate of the product gas, $\mathrm{Vg}\left(\mathrm{N} \mathrm{m}^{3} / \mathrm{s}\right)$, for a desired $\mathrm{LHVg}\left(\mathrm{MJ} / \mathrm{N} \mathrm{m}^{3}\right)$ is found by:

$\mathrm{Vg}=\left(\mathrm{Q} / \mathrm{LHV}_{\mathrm{g}}\right) \mathrm{N} \mathrm{m}^{3} / \mathrm{s}$

The net heating value or LHV of producer gas $\left(\mathrm{LHV}_{\mathrm{g}}\right)$ can be calculated from its composition.

\section{Fuel feed rate}

To find the biomass feed rate $\mathrm{M}_{\mathrm{f}}$, the required power output is divided by the LHV of the biomass $\left(\mathrm{LHV}_{\mathrm{bm}}\right)$ and by the gasifier efficiency, $\eta_{\text {gef }}$. 
$\mathrm{M}_{\mathrm{f}}=\left(\mathrm{Q} / \mathrm{LHV}_{\mathrm{bm}} \times \eta_{\text {gef }}\right)$

The LHV may be related to the higher heating value (HHV) and its hydrogen and moisture contents as:

$\mathrm{LHV}_{\mathrm{bm}}=\mathrm{HHV}_{\mathrm{daf}}-20,300 \times \mathrm{H}_{\mathrm{daf}}-2260 \times$ $\mathrm{M}_{\mathrm{daf}}$

Here, $\mathrm{H}_{\text {daf }}$ is the hydrogen mass fraction in the fuel, $\mathrm{M}_{\mathrm{daf}}$ is the moisture mass fraction, and $\mathrm{HHV}_{\text {daf }}$ is the $\mathrm{HHV}$ in $\mathrm{kJ} / \mathrm{kg}$ on a dry on moisture-ash-free basis. By using the definition of these, one can relate the HHV on moisture ash- free basis to that on only drybasis value as:

$\mathrm{HHV}_{\text {daf }}=\mathrm{HHV}_{\mathrm{d}}[(1-\mathrm{M}) /(1-$ Ash- M $)]$

Where the subscripts,

$d$ and $d a f$ refer to dry and moisture-ash-free basis respectively;

$M$ is the moisture fraction;

and $A S H$ is the ash fraction in fuel on a rawfuel basis.

On a dry basis, $\mathrm{HHV}_{\mathrm{d}}$ is typically in the range $1821 \mathrm{MJ} / \mathrm{kg}$ (Van Loo and Koppejan, 2003). It may be calculated from the ultimate analysis for the biomass using the following equation (Van Loo and Koppejan, 2003):

$\mathrm{HHV}_{\mathrm{d}}=0.3491 \mathrm{C}+1.1783 \mathrm{H}+0.1005 \mathrm{~S}-0.0151 \mathrm{~N}-$ 0.1034O- 0.0211ASH

Where $\mathrm{C}, \mathrm{H}, \mathrm{S}, \mathrm{N}, \mathrm{O}$, and $\mathrm{ASH}$ are the mass fraction of carbon, hydrogen, sulfur, nitrogen, oxygen, and ash in the fuel on a dry basis.

\section{Flow rate of gasifying medium}

The amount of gasification medium has a major influence on yield and composition of the product gas.

\section{Air}

The theoretical air requirement for complete combustion of a unit mass of a fuel, $\mathrm{m}_{\mathrm{th}}$, is an important parameter. It is known as the stoichiometric air requirement. Its calculation is shown in equation. For an air-blown gasifier operating, the amount of air required, $\mathrm{M}_{\mathrm{a}}$, for gasification of unit mass of biomass is found by multiplying it by another parameter equivalence ratio (ER):

$\mathrm{M}_{\mathrm{a}}=\mathrm{m}_{\mathrm{th}} \mathrm{ER}$

For a fuel feed rate of $\mathrm{M}_{\mathrm{f}}$, the air requirement of the gasifier, $\mathrm{M}_{\mathrm{fa}}$, is:

$\mathrm{M}_{\mathrm{fa}}=\mathrm{m}_{\mathrm{th}} \mathrm{ER} \times \mathrm{M}_{\mathrm{f}}$

For a biomass gasifier, 0.25 may be taken as a first-guess value for ER.

\section{Equivalence ratio}

Equivalence ratio (ER) is an important design parameter for a gasifier. It is the ratio of the actual air fuel ratio to the stoichiometric air fuel ratio. This definition is the same as that of excess air (EA) used for a combustion system, except that it is used only for airdeficient situations, such as those found in a gasifier.

$\mathrm{ER}(<1.0)$ gasification $=$ actual air/ stoichiometric air $=\mathrm{EA}(>1.0)$ combustion

In a combustor, the amount of air supplied is determined by the stoichiometric (or theoretical) amount of air and its excess air coefficient. In a gasifier, the air supply is only a fraction of the stoichiometric amount. The stoichiometric amount of air is calculated based on the ultimate analysis of the fuel. ER dictates the performance of the gasifier. For example, pyrolysis takes place in the absence of air and hence the ER is zero; for 
gasification of biomass, it lies between 0.2 and 0.3 .

In up draft gasifier which typically operate with an ER of less than 0.25, have higher tar content. With an ER above 0.25, some product gases are also burnt, increasing the temperature. The quality of gas obtained from a gasifier strongly depends on the value of ER, which must be significantly below 1.0 to ensure that the fuel is gasified rather than combusted. However, an excessively low ER value (0.2) results in several problems, including incomplete gasification, excessive char formation, and a low heating value of the product gas. On the other hand, too high and ER (0.4) results in excessive formation of products of complete combustion, such as $\mathrm{CO}_{2}$ and $\mathrm{H}_{2} \mathrm{O}$, at the expense of desirable products, such as $\mathrm{CO}$ and $\mathrm{H}_{2}$. This causes a decrease in the heating value of the gas. In this gasification system the ER's value is normally maintained within the range of 0.20 to 0.30 .

Besides supplying the energy for the endothermic gasification reactions, the gasifier must provide energy to raise the feed and gasification medium to the reaction temperature, as well as to compensate for the heat lost to the reactor walls. For a selfsustained gasifier, part of the chemical energy in the biomass provides the heat required. The total heat necessary comes from the oxidation reactions. The energy balance of the gasifier is thus the main consideration in determining the oxygen-to-carbon $(\mathrm{O} / \mathrm{C})$ ratio.

Equilibrium calculations can show that as the $\mathrm{O} / \mathrm{C}$ ratio in the feed increases, $\mathrm{CH}_{4}, \mathrm{CO}$, and hydrogen in the product decreases but $\mathrm{CO}_{2}$ and $\mathrm{H}_{2} \mathrm{O}$ in the product increases. Beyond an $\mathrm{O} / \mathrm{C}$ ratio of 1.0 , hardly any $\mathrm{CH}_{4}$ is produced. When air is the gasification medium, as is the case for $70 \%$ of all gasifiers (Ciferno and Marano, 2002), the nitrogen in it dilutes the product gas. The heating value of the gas is therefore relatively low $\left(46 \mathrm{MJ} / \mathrm{m}^{3}\right)$.

\section{Reactor diameter (D)}

Diameter refers to the size of the reactor in terms of the diameter of the cross-section of the cylinder where the fuel is being burned. This is a function of the amount of the fuel consumed per unit time (FCR) to the specific gasification rate (SGR) of the fuel ranging from 100 to $250 \mathrm{~kg} / \mathrm{m}^{2}-\mathrm{h}$

The reactor diameter is computed using the formula with

$\mathrm{D}=[(4 \times \mathrm{FCR}) / \mathrm{SGR} \times \pi]^{0.5}$

FCR - fuel consumption rate

SGR - [weight of the biomass fuel used, $\mathrm{Kg} /$ (Reactor area $\mathrm{m}^{2} \times$ Reactor diameter $-0.15 \mathrm{~m}$ operating time, $\mathrm{h}]$

\section{Height of the reactor $(\mathrm{H})$}

Height refers to the total distance from the top and the bottom end of the reactor. This determines how long would the gasifier be operated in one loading of fuel. Basically, it is a function of a number of variables such as the required time to operate the gasifier $(\mathrm{T})$, the specific gasification rate (SGR), and the density of the fuel. As shown below, the height of the gasifier is computed using the formula

$\mathrm{H}=\left[(\mathrm{SGR} \times \mathrm{T}) / \rho_{\mathrm{f}}\right]$

For a desired operating time of the gasifier of 2.5 hours, assuming the density of the fuel $300 \mathrm{~kg} / \mathrm{m}^{3}$.

\section{Time to consume the fuel}

Time refers to the total time required to completely gasify the fuel inside the reactor. This includes the time to ignite the fuel and 
the time to generate gas, plus the time to completely burn all the fuel in the reactor. The density of the fuel $\left(\rho_{\mathrm{f}}\right)$ the volume of the reactor $\left(\mathrm{V}_{\mathrm{r}}\right)$ and the fuel consumption rate (FCR) are the factors used in determining the total time to consume the fuel in the reactor. This is computed using the formula

$\mathrm{T}=\left[\left(\rho_{\mathrm{f}} \times \mathrm{V}_{\mathrm{r}}\right) / \mathrm{FCR}\right.$

\section{Amount of air needed for gasification - Air Flow Rate (AFR)}

AFR refers to the rate of flow of air needed to gasify the fuel. This is very important in determining the size of the fan or of the blower needed for the reactor in gasifying the fuel. This can be simply determined using the rate of consumption of the fuel (FCR), the stoichiometric air of the fuel (SA), density of air $\left(\rho_{\mathrm{f}}\right.$ and the recommended equivalent ratio ( $\varepsilon$ ) for gasifying wood fuel of 0.3 to 0.5 . This is obtained using the formula

$\mathrm{V}_{\mathrm{s}}=$ Air flow rate / area of the reactor

Figure 1 shows the designed updraft gasifier with blower and K-thermocouple were fixed data logger to measure the temperature within the system.

\section{Dimensions of the updraft gasifier}

\begin{tabular}{|l|l|}
\hline $\begin{array}{l}\text { Diameter of the } \\
\text { Reactor }\end{array}$ & $0.6 \mathrm{~m}$ \\
\hline Height of the reactor & $1 \mathrm{~m}$ \\
\hline $\begin{array}{l}\text { Fuel consumption } \\
\text { ratio }\end{array}$ & $30 \mathrm{~kg} / \mathrm{h}$ \\
\hline $\begin{array}{l}\text { Time to consume the } \\
\text { fuel }\end{array}$ & $2.45 \mathrm{hours}$ \\
\hline Air Flow Rate (AFR) & $0.347 \mathrm{~m}^{3} / \mathrm{sec}$ \\
\hline
\end{tabular}

\section{Results and Discussion}

For updraft gasifier, the operation condition is mainly adjusted by regulating the air flow rate entering into the gasifier. The air flow rate is the most important parameter during the actual operation process of the gasifier. It is closely related to the temperature distribution of the gasifier, product gas composition and LHV shows the temperature of the combustion zone and gasification intensity under different air flow rates. Air flow rate increasing from 21 to $28 \mathrm{~m}^{3} / \mathrm{h}$, the temperature of the oxidation zone increased sharply from 600 to $1025^{\circ} \mathrm{C}$, and the gasification intensity enhanced largely from 98 to $456 \mathrm{~kg} / \mathrm{h} \mathrm{m}^{2}$, thus verifying that the temperature of the combustion zone could directly reflect the intensity of the gasification process. Considering that the ash fusion point of the coconut shell used in the experiment is $1100^{\circ} \mathrm{C}$, the air flow rate chosen for this gasifier should not exceed $28 \mathrm{~m}^{3} / \mathrm{h}$. An air flow rate of $25-28 \mathrm{~m}^{3} / \mathrm{h}$ might be the appropriate range due to the proper oxidation zone temperature and gasification intensity. Besides, more air entering into the gasifier, more biomass would react. The temperature level would be higher thus leading each zone inside the gasifier to be expanded and the gas production to increase.

The ER is pivotal for achieving a proper gas quality as it identifies the optimum air/fuel ratio for a given biomass gasifier system. In this gasifier the air inlet valve can be adjusted to control the air flow rate into the reactor, however the fuel feed rate cannot be controlled and it is entirely dependent on the behavior of the fuel wood during gasification. ER 0.4, there was an increase in the $\mathrm{H}_{2}$ and $\mathrm{CO}$ concentrations from $16 \%$ and $15 \%$ respectively. As the ER decreased from 0.6 to 0.5 however, the concentration of $\mathrm{CO}_{2}$ increased from 16 to $15 \%$ whilst that of $\mathrm{H}_{2}$ and $\mathrm{CO}$ decreased. This occurred since the amount of air being supplied relative to the fuel was more than that required for gasification; as a consequence of the higher partial pressure of $\mathrm{O}_{2}$ in the gasifier, combustion reactions enhanced, oxidizing some of the $\mathrm{H}_{2}$ to $\mathrm{H}_{2} \mathrm{O}$ and the char to $\mathrm{CO}_{2}$. 


\section{Dimensions of the updraft gasifier}

\begin{tabular}{|l|l|}
\hline Diameter of the Reactor & $0.6 \mathrm{~m}$ \\
\hline Height of the reactor & $1 \mathrm{~m}$ \\
\hline Fuel consumption ratio & $30 \mathrm{~kg} / \mathrm{h}$ \\
\hline Time to consume the fuel & $2.45 \mathrm{hours}$ \\
\hline Air Flow Rate (AFR) & $0.03 \mathrm{~m}^{3} / \mathrm{sec}$ \\
\hline Temperature range & 900 to $1150^{\circ} \mathrm{C}$ \\
\hline
\end{tabular}

Fig.1 Designed updraft gasifier

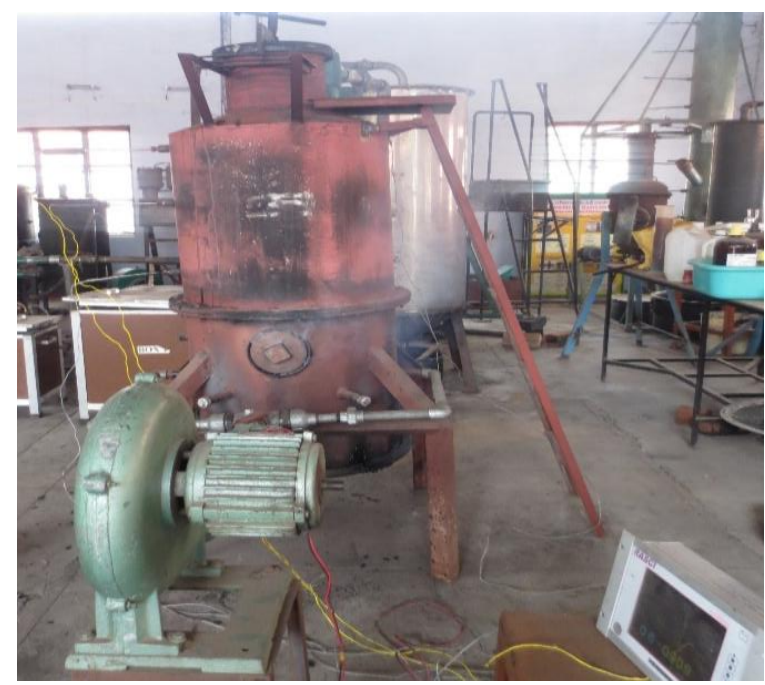

\section{Required air flow rate for the coconut shell}

Air flow rate for coconut shell $-1.695 \mathrm{~kg}$ of air / $\mathrm{kg}$ of coconut shell

From one $\mathrm{kg}$ of coconut shell we can get 2.6 $\mathrm{Nm}^{3}$ of producer gas

In conclusion an updraft gasifier utilizing thermally thick large size solid biomass fuel has been developed and evaluated with field test results. The gasifier obtained high-energy release rates due to the high inlet air velocity and activated/extended reaction in combustion and reduction zones. The lowest portion of the bed is an oxidizing region and the remainder of the bed acts as gasification and drying zone for the design case with $20 \%$ fuel moisture. It was found that air flow rate directly affects the gasification temperature and operation condition. The operating characteristics of this type of gasifier provide a range of options for bed height as well as under fire airflow rate to obtain a desired heat release rate. This flexibility in operating condition is a significant aid in the design and start-up of the unique type of biomass power source. Air to fuel ratio would be a more useful measure when moisture is present in the lower portion of the bed to maximize/minimize specific gasification products.

Major factors that affect efficiency of gasifier performance are dry flue gas, moisture in fuel, latent heat, unburned fuel, radiation depending on the fuel properties.

The factors that mainly affect the gasifier performance can be rectified to improve the efficiency. 


\section{References}

Ciferno, J.P., Marano, J.J. 2002. Benchmarking Biomass Gasification Technologies for Fuels, Chemicals and Hydrogen Production. U.S. Department of Energy, National Energy Technology Laboratory, http://seca.doe.gov/technologies/coalpo wer.

Di Blasi, C. 2004. Modeling wood gasification in a countercurrent fixedbed reactor. AIChE J., 9: 2306-9.

Ghosh, D., Sagara, A.D., Kishore, V.V.N. 2006. Scaling up biomass gasifier use: an application-specific approach. Energy Policy, 43: 66-82.

Ismail, T.M., El-Salam, M.A. 2014. A numerical model simulation for an updraft gasifier using high temperature steam. Int. J. Mech. Aerosp. Ind. Mechatron Eng., 8(5): 831-7.

James, A., Yuan, W., Boyette, M., Wang, D., Kumar, A. 2014. In-chamber thermocatalytic tar cracking in an updraft biomass gasifier. Int. J. Agric. Biol. Eng., [in press].

Kucuk, M.M., Demirbas, A. 1997. Biomass conversion processes. Energy Conversat. Mgmt, 38: 151-65.

Nsamba, H.K., Hale, S.E., Cornelissen, G., Bachmann, R.T. 2015. Designing and performance evaluation of biochar production in a top-lit updraft upscaled gasifier. J. Sustain Bioenergy Syst., 5:
41-55.

Pathak, B., Chaudhari, S., Fulekar, M.H. 2013. Biomass - resource for sustainable development. Int. J. Adv. Res. Technol., 2(6): 271-87.

Prabir Basu. 2013. Hand book on Biomass Gasification, Pyrolysis and Torrefaction. Academic Press is an Imprint of Elesvier, 32 jamestown Road, London NW 17BY, UK, 525 B street, suite 1800, San Diego, CA 92101-4495, USA.

Raja, R.C,. Sankarabharathi, S., Sankar, R.R., Chandraseka, M. 2015. Performance of the pilot model updraft gasifier. $J$. Chem. Pharm. Sci., 6: 177-82.

Sims, R.E.H. 2003.Energy and fuel wood. New Zealand: Centre for Energy Research, Massey University.

Umeki, .K, Namioka, T., Yoshikawa, K. 2012. Analysis of an updraft biomass gasifier with high temperature steam using a numerical model. Appl. Energy, 90: 38-45.

Van Loo, S., Koppejan, J. 2003. Handbook on Biomass Combustion and Cofiring. Task 32. International Energy Agency (IEA), Twente University Press, Enschede, The Netherlands.

Yadav, P., Dutta, A., Gupta, B., Pandey, M. 2013. Performance analysis of the constructed updraft biomass gasifier for three different biomass fuels. Int. J. Mod. Eng. Res., 3(4): 2056-61.

\section{How to cite this article:}

Preetha Devi, R. and Kamaraj, S. 2017. Design and Development of Updraft Gasifier Using Solid Biomass. Int.J.Curr.Microbiol.App.Sci. 6(4): 182-189.

doi: https://doi.org/10.20546/ijcmas.2017.604.021 